\title{
Physical Growth of High Altitude Spitian Boys
}

\author{
Promila Malhotra, Prit Pal Singh*, S.P. Singh and L.S. Sidhu \\ Department of Human Biology, Punjabi University, Patiala, Punjab, India \\ *Public College, Samana, Punjab, India
}

KEYWORDS Physical Growth. High Altitude. Hypoxia. Adaptation. Spiti Valley. Himalayas

\begin{abstract}
The present study is an effort to explore the effect of high altitude on the physical growth of Spitian children. The present cross sectional study has been conducted on Spitian boys, ranging in age from 5 to 20 years. Anthropometric data was collected on 636 subjects during 1996-1998 from various areas of Spiti valley by PPS. The altitudes of these areas range between $3500-4200$ metres above mean-sea-level. The adolescent spurt in case of Spitian boys occurs at 15-16 years of age in weight and 13-14 years in height whereas the peak adolescent gain in chest circumference is even later and takes place at 17-18 years. It can be concluded from the above results that the adolescent spurt is delayed in Spitian boys. The proportionally greater chest cage size has emerged as the most important morphological characteristic in various studies. This seems to be an adaptation to low partial pressure of oxygen. A very late adolescent spurt in chest circumference might be giving an edge to the high altitude populations to keep on adding to the final adult dimensions by way of extending the growth period.
\end{abstract}

\section{INTRODUCTION}

The high altitudinal zones of the world present very difficult and harsh weather conditions to the animals and humans alike. Nevertheless vast areas with these environmental conditions have long been inhabited. Surviving and procreating in such regions virtually requires marvellous adaptive flexibility of the organisms. What are the common stresses of all high altitude regions? These include low barometric pressure, cold climate, high velocity winds, increased intensity of UV radiation, rugged terrain, increased precipitation (snow, hailstorm, sleet), isolation, limited energy production, desert and arid conditions. If survival in these regions is difficult, then growing and developing phenomena are all the more affected. All these conditions affect the growth and development of children in such way that it slows down the process of maturation and depresses the overall growth. Andean, Alps and Himalayan high altitude zones have very extensively been studied by various authors to explore the growth and development of children.

The findings from different high altitude zones have generally indicated that the children have a prolonged period of growth, late and poorly defined adolescents spurt, relatively bigger chests and calf muscles, greater lung capacity and relatively thinner fatfolds than those inhabiting sea level or lower altitudes (Frisancho and Baker, 1970; Clegg et al., 1972; Greksa, 1990; Hoff, 1973; Beall et al., 1977; Miklashevskaya,
1977; Malik and Singh, 1978, 1979; Malik and Hauspie, 1986; Singh, 1980, 1989; Singh et al., 1986; Basu and Gupta, 1984; Bhasin and Singh, 1992). The only exception seems to be that of the Ethiopian highlands where the high altitude children grow favourably to their lowland counterparts (Harrison et al., 1969).

The children of Spiti valley inhabiting high altitudes have never been studied before therefore the present study would explore the effect of high altitude on the physical growth of Spitian children. It may be mentioned here that Spiti valley is in geographical proximity to the Tibetan Province of People's Republic of China.

\section{MATERIAL AND METHODS}

The present cross sectional study has been conducted on Spitian boys, ranging in age from 5 to 20 years. Anthropometric data was collected on 636 subjects during 1996-1998 from various areas of Spiti valley by PPS. The altitudes of these areas range between $3500-4200$ metres above mean-sea-level. The age of the child was calculated from the date of birth, which was taken from the school registers in case of school going children and from the parents of those children who did not attend the school. Yearly age groups were formed so as the mid-point coincided with the whole year figure, e.g., all subjects from 4.500 to 5.499 years were included in 5- year age group, those from 5.500 to 6.499 years in the 6- year age group and so on. The measurements were taken following the 
techniques of Weiner and Lourie (1969) and bilaterally represented measurements were taken using Heath and Carter (1967) method.

\section{RESULTS}

Table 1 provides information about mean and SD of body mass of Spitian males ranging in age from 5 years to 20 years. It has been observed that at the age of 5 years, the mean value of body weight is $16.292 \mathrm{~kg}$ which increases to 52.020 $\mathrm{kg}$ at the age of 19 years indicating a pattern of general increase in body mass from 5 years to 20 years. Thus the total percentage gain between 5 and 19 years is $68.68 \%$ of the maximum adult value obtained at the age of 19 years. The maximum yearly gain in weight of $4.72 \mathrm{~kg}$ takes place during 15-16 years age interval indicating the peak of adolescent growth spurt.

Table 1: Body Mass (kg) of Spitian males.

\begin{tabular}{lcccrrr}
\hline $\begin{array}{l}\text { AgeNum- } \\
\text { (yr) } \text { ber }\end{array}$ & Mean & S.D. & $\begin{array}{c}\text { S.E. } \\
M .\end{array}$ & C.V. & $\begin{array}{c}\text { Gain/ } \\
y r .\end{array}$ \\
\hline 5 & 37 & 16.292 & 1.56 & 0.26 & 9.58 & - \\
6 & 37 & 17.487 & 2.10 & 0.34 & 12.01 & 1.20 \\
7 & 40 & 19.725 & 2.77 & 0.44 & 14.04 & 2.24 \\
8 & 40 & 20.638 & 2.18 & 0.34 & 10.56 & 0.91 \\
9 & 36 & 23.250 & 1.78 & 0.30 & 7.66 & 2.61 \\
10 & 36 & 24.986 & 3.13 & 0.52 & 12.53 & 1.74 \\
11 & 46 & 27.361 & 4.47 & 0.66 & 16.34 & 2.38 \\
12 & 70 & 30.257 & 5.40 & 0.64 & 17.85 & 2.90 \\
13 & 37 & 31.662 & 5.30 & 0.87 & 16.74 & 1.41 \\
14 & 33 & 36.197 & 5.51 & 0.96 & 15.22 & 4.54 \\
15 & 38 & 38.474 & 7.74 & 1.26 & 20.12 & 2.28 \\
16 & 45 & 43.189 & 5.80 & 0.87 & 13.43 & 4.72 \\
17 & 40 & 45.863 & 6.44 & 1.02 & 14.04 & 2.67 \\
18 & 38 & 47.566 & 6.49 & 1.05 & 13.64 & 1.70 \\
19 & 33 & 52.020 & 4.84 & 0.84 & 9.30 & 4.45 \\
20 & 30 & 51.417 & 5.53 & 1.01 & 10.76 & -0.60 \\
\hline
\end{tabular}

The mean value of stature for Spitian males at the age of 5 years is $103.8 \mathrm{~cm}$, which increases to $162.3 \mathrm{~cm}$ at the age of 19 years (Table 2). The percentage gain during this period turns out to be $36.04 \%$ from the maximum value obtained at the age of 19 years. The gain per year is maximum $(7.10 \mathrm{~cm})$ during the age of 13-14 years.

The mean value of chest circumference is 54.1 $\mathrm{cm}$ at the age of 5 years for the Spitian males, and it increases continuously with the advancing age (Table 3). The mean value of chest circumference is $82.8 \mathrm{~cm}$ at the age of 20 years. Thus the total increment in chest girth during this period is 28.7 $\mathrm{cm}$ and when expressed in terms of percentage of the maximum adult value obtained at the age of 20 years, it comes out to be $33.45 \%$. The maximum
Table 2: Stature $(\mathrm{cm})$ of Spitian males.

\begin{tabular}{lcrrrrr}
\hline $\begin{array}{l}\text { AgeNum- } \\
\text { (yr) ber }\end{array}$ & Mean & S.D. & $\begin{array}{c}\text { S.E. } \\
\text { M. }\end{array}$ & C.V. & $\begin{array}{c}\text { Gain/ } \\
y r .\end{array}$ \\
\hline 5 & 37 & 103.8 & 5.10 & 0.84 & 4.91 & - \\
6 & 37 & 105.9 & 4.70 & 0.77 & 4.44 & 2.10 \\
7 & 40 & 113.5 & 6.92 & 1.09 & 6.10 & 7.60 \\
8 & 40 & 116.6 & 5.64 & 0.89 & 4.84 & 3.10 \\
9 & 36 & 122.5 & 4.01 & 0.67 & 3.27 & 5.90 \\
10 & 36 & 125.6 & 6.35 & 1.06 & 5.06 & 3.10 \\
11 & 46 & 132.6 & 7.98 & 1.18 & 6.02 & 7.00 \\
12 & 70 & 136.9 & 7.87 & 0.94 & 5.75 & 4.30 \\
13 & 37 & 139.7 & 7.71 & 1.27 & 5.52 & 2.80 \\
14 & 33 & 146.8 & 9.64 & 1.68 & 6.57 & 7.10 \\
15 & 38 & 150.1 & 9.88 & 1.60 & 6.58 & 3.30 \\
16 & 45 & 155.8 & 10.16 & 1.51 & 6.52 & 5.70 \\
17 & 40 & 158.1 & 8.18 & 1.29 & 5.17 & 2.30 \\
18 & 38 & 161.1 & 5.33 & 0.86 & 3.31 & 3.00 \\
19 & 33 & 162.3 & 4.44 & 0.77 & 2.74 & 1.20 \\
20 & 30 & 161.3 & 6.52 & 1.19 & 4.04 & -0.96 \\
\hline
\end{tabular}

Table 3: Chest Circumference $(\mathrm{cm})$ of Spitian males.

\begin{tabular}{llllllc}
\hline $\begin{array}{l}\text { AgeNum- } \\
(y r)\end{array}$ & ber & Mean & S.D. & $\begin{array}{c}\text { S.E. } \\
\text { M. }\end{array}$ & C.V. & Gain/ \\
$y r$.
\end{tabular}

gain per year in chest circumference is to the tune of $3.8 \mathrm{~cm}$ between $17-18$ years.

The 5 years old Spitian males have $13.8 \mathrm{~cm}$ mean for upper arm circumference (normal) which increase to $22.8 \mathrm{~cm}$ at the age of 20 years (Table 4). The total increase during this period is $9.0 \mathrm{~cm}$ and when expressed in terms of percentage it comes out to be $39.47 \%$ of the maximum mean value possessed at the age of 20 years.

The mean value of triceps skinfold at the age of 5 years in Spitian males is $7.86 \mathrm{~mm}$ (Table 5). On the whole, there is a general trend of decrease in skinfold thickness with age which is $6.09 \mathrm{~mm}$ at the age of 20 years. Thus a total decrement of $1.77 \mathrm{~mm}$ is recorded in triceps skinfold from 5 years to 20 years of age.

Table 6 shows the age trends of sub-scapular skinfolds for Spitian males ranging in age from 5 
Table 4: Upper Arm Circumference (cm) of Spitian males.

\begin{tabular}{|c|c|c|c|c|c|c|}
\hline \multicolumn{2}{|c|}{$\begin{array}{l}\text { AgeNum- } \\
(y r) \text { ber }\end{array}$} & Mean & S.D. & $\begin{array}{c}S . E . \\
M .\end{array}$ & C.V. & $\begin{array}{c}\text { Gain/ } \\
y r .\end{array}$ \\
\hline 5 & 37 & 13.8 & 0.81 & 0.13 & 5.87 & - \\
\hline 6 & 37 & 13.9 & 1.03 & 0.17 & 7.41 & 0.10 \\
\hline 7 & 40 & 14.4 & 1.02 & 0.16 & 7.08 & 0.50 \\
\hline 8 & 40 & 14.9 & 1.10 & 0.17 & 7.38 & 0.50 \\
\hline 9 & 36 & 15.0 & 0.93 & 0.15 & 6.18 & 0.14 \\
\hline 10 & 36 & 15.3 & 1.22 & 0.20 & 7.97 & 0.26 \\
\hline 11 & 46 & 15.8 & 1.63 & 0.24 & 10.32 & 0.50 \\
\hline 12 & 70 & 16.7 & 2.15 & 0.26 & 12.87 & 0.90 \\
\hline 13 & 37 & 16.8 & 1.20 & 0.20 & 7.14 & 0.10 \\
\hline 14 & 33 & 17.6 & 1.64 & 0.29 & 9.32 & 0.80 \\
\hline 15 & 38 & 18.6 & 2.13 & 0.35 & 11.45 & 1.00 \\
\hline 16 & 45 & 19.4 & 1.85 & 0.28 & 9.54 & 0.80 \\
\hline 17 & 40 & 20.2 & 2.79 & 0.44 & 13.81 & 0.80 \\
\hline 18 & 38 & 20.8 & 2.41 & 0.39 & 11.59 & 0.60 \\
\hline 19 & 33 & 21.5 & 1.74 & 0.30 & 8.09 & 0.70 \\
\hline 20 & 30 & 22.8 & 2.28 & 0.40 & 10.00 & 1.30 \\
\hline
\end{tabular}

Table 5: Triceps skinfold $(\mathrm{mm})$ of Spitian males.

\begin{tabular}{llllllr}
\hline $\begin{array}{l}\text { AgeNum- } \\
\text { (yr) ber }\end{array}$ & Mean & S.D. & $\begin{array}{c}\text { S.E. } \\
\text { M. }\end{array}$ & C.V. & $\begin{array}{c}\text { Gain/ } \\
y r .\end{array}$ \\
\hline 5 & 37 & 7.86 & 1.74 & 0.29 & 22.14 & - \\
6 & 37 & 7.88 & 1.45 & 0.24 & 18.40 & 0.02 \\
7 & 40 & 6.55 & 1.47 & 0.23 & 22.44 & -1.33 \\
8 & 40 & 6.59 & 1.62 & 0.26 & 24.58 & 0.04 \\
9 & 36 & 6.57 & 1.40 & 0.23 & 21.31 & -0.02 \\
10 & 36 & 6.97 & 1.96 & 0.33 & 28.12 & 0.40 \\
11 & 46 & 6.43 & 2.24 & 0.33 & 34.84 & -0.54 \\
12 & 70 & 6.82 & 1.95 & 0.23 & 28.59 & 0.39 \\
13 & 37 & 7.22 & 2.13 & 0.35 & 29.50 & 0.40 \\
14 & 33 & 6.43 & 2.06 & 0.36 & 32.04 & -0.79 \\
15 & 38 & 6.13 & 1.19 & 0.19 & 19.41 & -0.30 \\
16 & 45 & 6.05 & 1.83 & 0.27 & 30.25 & -0.08 \\
17 & 40 & 6.13 & 1.29 & 0.20 & 21.04 & 0.08 \\
18 & 38 & 6.12 & 1.24 & 0.20 & 20.26 & -0.01 \\
19 & 33 & 6.34 & 1.79 & 0.31 & 28.23 & 0.22 \\
20 & 30 & 6.09 & 1.20 & 0.22 & 19.70 & -0.25 \\
\hline
\end{tabular}

years to 20 years. At the age of 5 years the mean value of subscapular fatfold is $5.89 \mathrm{~mm}$ which decreases to $4.76 \mathrm{~mm}$ at the age of 9 years. Thereafter a general trend of increase is noticed and the subscapular skinfold reaches a value of $7.01 \mathrm{~mm}$ at the age of 19 years.

The mean suprailiac skinfold thickness in Spitian males at 5 years of age is $5.74 \mathrm{~mm}$ and at the age of 20 years it is $5.98 \mathrm{~mm}$ (Table 7). From 5 to 8 years the skinfold decreases gradually in each year however, afterwards it steadily increases to $6.78 \mathrm{~mm}$ at the age of 19 years.

\section{DISCUSSION}

The adolescent spurt in case of Spitian boys occurs at 15-16 years of age in weight and 13-14
Table 6: Sub-scapular skinfold (mm) of Spitian males.

\begin{tabular}{llllllr}
\hline $\begin{array}{l}\text { AgeNum- } \\
\text { (yr) }\end{array}$ & ber & Mean & S.D. & $\begin{array}{c}\text { S.E. } \\
\text { M. }\end{array}$ & C.V. & $\begin{array}{c}\text { Gain/ } \\
y r .\end{array}$ \\
\hline 5 & 37 & 5.89 & 1.44 & 0.24 & 24.45 & - \\
6 & 37 & 5.54 & 1.40 & 0.23 & 25.27 & -0.35 \\
7 & 40 & 4.87 & 0.89 & 0.14 & 18.28 & -0.67 \\
8 & 40 & 4.87 & 1.00 & 0.16 & 20.53 & 0.00 \\
9 & 36 & 4.76 & 0.85 & 0.14 & 17.86 & -0.11 \\
10 & 36 & 4.78 & 1.83 & 0.20 & 38.28 & 0.02 \\
11 & 46 & 5.31 & 1.32 & 0.19 & 24.86 & 0.53 \\
12 & 70 & 5.51 & 2.02 & 0.24 & 36.66 & 0.20 \\
13 & 37 & 5.65 & 0.89 & 0.15 & 15.75 & 0.14 \\
14 & 33 & 5.73 & 1.36 & 0.24 & 23.73 & 0.08 \\
15 & 38 & 5.65 & 1.24 & 0.20 & 21.95 & -0.08 \\
16 & 45 & 5.93 & 0.77 & 0.12 & 12.98 & 0.28 \\
17 & 40 & 6.69 & 1.48 & 0.23 & 22.12 & 0.76 \\
18 & 38 & 6.84 & 1.68 & 0.27 & 24.56 & 0.15 \\
19 & 33 & 7.01 & 2.07 & 0.36 & 29.53 & 0.17 \\
20 & 30 & 6.90 & 2.28 & 0.42 & 33.04 & -0.11 \\
\hline
\end{tabular}

Table 7: Supra-iliac skinfold (mm) of Spitian males.

\begin{tabular}{llllllr}
\hline $\begin{array}{l}\text { AgeNum- } \\
\text { (yr) }\end{array}$ & Mer & Mean & S.D. & $\begin{array}{c}\text { S.E. } \\
\text { M. }\end{array}$ & C.V. & $\begin{array}{c}\text { Gain/ } \\
y r .\end{array}$ \\
\hline 5 & 37 & 5.74 & 2.12 & 0.35 & 36.93 & - \\
6 & 37 & 5.72 & 1.38 & 0.23 & 24.13 & -0.02 \\
7 & 40 & 4.73 & 1.26 & 0.20 & 26.64 & -0.99 \\
8 & 40 & 4.56 & 1.34 & 0.21 & 29.39 & -0.17 \\
9 & 36 & 4.89 & 1.30 & 0.22 & 26.58 & 0.33 \\
10 & 36 & 5.32 & 1.63 & 0.27 & 30.64 & 0.43 \\
11 & 46 & 5.31 & 2.67 & 0.39 & 50.28 & -0.01 \\
12 & 70 & 5.27 & 2.59 & 0.31 & 49.15 & -0.04 \\
13 & 37 & 5.32 & 1.14 & 0.19 & 21.43 & 0.05 \\
14 & 33 & 5.08 & 1.31 & 0.23 & 25.79 & -0.24 \\
15 & 38 & 5.14 & 1.07 & 0.17 & 20.82 & 0.06 \\
16 & 45 & 5.73 & 1.22 & 0.18 & 21.29 & 0.59 \\
17 & 40 & 6.65 & 2.23 & 0.35 & 33.53 & 0.92 \\
18 & 38 & 6.31 & 1.63 & 0.26 & 25.83 & -0.34 \\
19 & 33 & 6.78 & 1.83 & 0.32 & 26.99 & 0.47 \\
20 & 30 & 5.98 & 1.33 & 0.24 & 22.24 & -0.80 \\
\hline
\end{tabular}

years in height whereas the peak adolescent gain in chest circumference is even later and takes place at 17-18 years. Though the cross-sectional nature of data does not warrant an accurate assessment of the velocity, yet some idea about the time of adolescent spurt can definitely be made. It can be concluded from the above results that the adolescent spurt is delayed in Spitian boys.

Growth pattern of high altitude children especially during adolescence is highly sensitive to environmental stresses as compared to childhood years (Beall et al., 1977; Wolanski, 1975; Wolanski and Malik, 1979). Many Himalayan populations do not show clear adolescent spurt such as Bods of Leh, Ladakh (Malik and Singh, 1978, 1979; Malik 1987; Bhasin and Singh, 1992), 
Baltis of Kargil (Bhasin and Singh, 1992), Tibetans of Dalhousie (Singh, 1989) and Rajput boys of Kullu Valley (Singal and Sidhu, 1983). Similarly, Andean populations do not show well defined adolescent growth spurt (Baker, 1969, 1984; Frisancho, 1970, 1975; Frisancho and Baker 1970; Frisancho et al., 1975; Clegg et al., 1970; Hoff, 1973; Beall et al., 1977 and Leatherman et al., 1995). Similarly delayed adolescent spurt has earlier been reported from almost all high altitude zones of the world (Frisancho and Baker, 1970; Clegg et al., 1972; Greksa, 1990; Hoff, 1973; Beall et al., 1977; Miklashevskaya, 1977; Malik and Singh, 1978, 1979; Malik and Hauspie, 1986; Singh, 1980, 1989; Singh et al., 1986; Basu and Gupta, 1984; Bhasin and Singh, 1992). Some hints about bimodal adolescent spurt in the present population are also available, however, only in-depth longitudinal studies can reveal the real situation. It may be mentioned that the high altitude Bods of Leh studied by Malik and Singh $(1978,1979)$ have also earlier presented facts leading the authors to conclude about the existence of bimodal adolescent spurt. It has been hypothesized that the nutritional and hypoxic stresses may have some role to play in delaying and modifying the adolescent spurt.

In the absence of suitable controls living at sea level or at low altitude to Spitian children, proportional values to height were calculated which, it is assumed, would throw more light on the facts. Therefore chest circumference to height ratio was used for comparisons. A comparison of chest/height ratio shows that the proportional chest circumference to height was greater in males of the present study as compared to boys of Punjab plains (Mandira, 1992), All India boys (ICMR, 1972), Gaddis and Kanets of moderate altitudes (Singh, 1980; Malhotra, 1975). On the other hand, high altitude Nunoa of Peru (Frisancho and Baker, 1970), and Bods of Leh (Bhasin and Singh, 1992) have higher chest girth/ height ratio to that of the boys of the present study. The proportionally greater chest cage size has emerged as the most important morphological characteristic in various studies (Frisancho and Baker, 1970; Clegg et al., 1972; Greksa, 1990; Hoff, 1973; Beall et al., 1977; Miklashevskaya, 1977; Malik and Singh, 1978, 1979; Singh, 1989; Basu and Gupta, 1984; Bhasin and Singh, 1992). This seems to be an adaptation to low partial pressure of oxygen. The percentage oxygen saturation of haemoglobin at a partial pressure of the oxygen of $100 \mathrm{mmHg}$ in the alveolar air at sea-level is about $97.5 \%$. The partial pressure of oxygen in the alveolar air is around $51 \mathrm{mmHg}$ at an altitude of $4500 \mathrm{~m}$ above mean-sea-level. The percentage saturation of oxygen in haemoglobin at partial pressure of oxygen of $51 \mathrm{mmHg}$ is around $84 \%$ (Ganong, 1991). It translates into 13\% less saturation of haemoglobin and hence the oxygen delivery to the tissues is dramatically reduced which interferes in the physiological functioning. In order to compensate for this, the larger chests

Table 8: Comparison of Chest circumference/height ratio of Spitian Males with other populations.

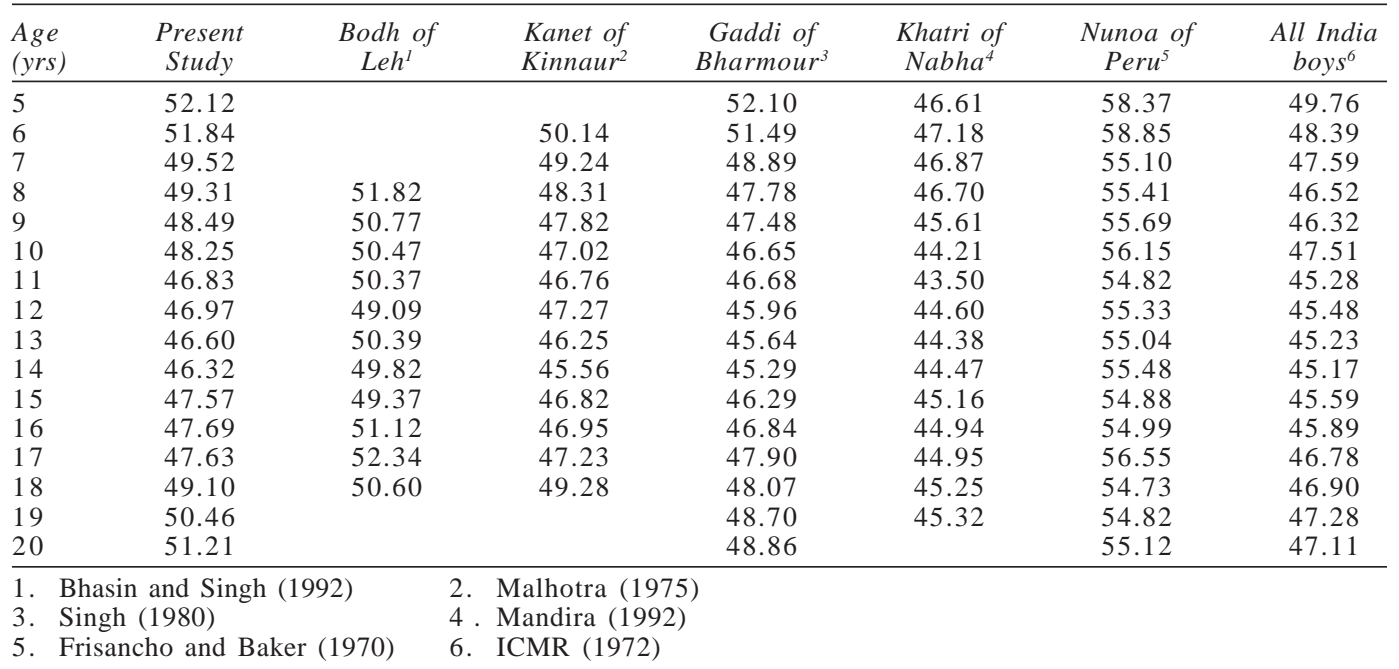


have evolved as an evolutionary consequence. A very late adolescent spurt in chest circumference might be giving an edge to the high altitude populations to keep on adding to the final adult dimensions by way of extending the growth period.

\section{ACKNOWLEDGEMENTS}

The work has been carried out under a project of the Indian Council of Medical Research, New Delhi entitled "Ecobiology and Health of High altitude Spitians - A Himalayan Tribe (No. 51/ 2/91-BMS-II)". The authors sincerely thank ICMR for the financial support.

\section{REFERENCES}

Basu, A. and Gupta, R.: Comments on high altitude hypoxia, culture, and human fecundity/ fertility. Am. Anthrop., 86: 994-996 (1984).

Beall, C.M., Baker, P.T., Baker, T.S. and Hass, J.D.: The effects of high altitude on adolescent growth in Southern Peruvian Amerindians. Hum. Biol., 49: 109124 (1977).

Bhasin, M.K. and Singh, L.P.: Study of physical growth and respiratory functions in two high-altitude populations - Boths and Baltis of Ladakh, Jammu and Kashmir, India. J. Hum. Ecol., 3: 27-34 (1992).

Clegg, E.J., Pawson, I.G., Ashtom, E.H. and Flinn, R.M. The growth of children at different altitudes in Ethiopia. Phil. Trans. R. Soc. Lond.,B. 264: 403437 (1972).

Frisancho, A.R. and Baker, P.T.: Altitude and growth - A study of the pattern of physical growth of a high altitude Peruvian Quechua population. Am. J. Phys. Anthrop., 32: 279-292 (1970).

Ganong, W.F. Review of Medical Physiology. Lange Medical Publications, U.S.A. (1991)

Greksa, L.P.: Developmental responses to high altitude hypoxia in Bolivian children of European ancestry: A test of the developmental adaptation hypothesis. Am. J. Hum. Biol., 2: 603-612 (1990).

Harrison, G.A., Kuchemann, C.F., Moore, A.S., Boyce, A.J., Baju, T., Mourant, A.E., Godber, M.J., Glasgow,
B.G., Kopec, A.C., Tills, D. and Clegg, E.J.: The effect of altitudinal variation in Ethiopian populations. Philos. Transac. Roy. Soc., London B, 256: 147-182 (1969).

Heath, B.H. and Carter, J.E.L.: A modified somatotype method. Am. J. Phys. Anthrop., 27: 57-74 (1967).

Hoff, C.: Altitudinal variations in the physical growth and development of Peruvian Quechua. Homo, 24: 87-99 (1973).

ICMR: Growth and physical development of Indian infants and children. Tech. Report Series No. 18, N.D. (1972).

Malhotra, R.: A study of physical growth and developmental status of a high altitude population in the Himalayas (a cross-sectional study of Kinnaura male Rajputs. Ph.D. Thesis (Unpublished), Panjab Univ., Chandigarh, India (1975).

Malik, S.L. and Hauspie, R.C.: Age at menarche among high altitude Bods of Ladakh (India). Hum. Biol, 58(4): $541-548$ (1986).

Malik, S.L. and Singh, I.P.: Growth trends among male Bods of Ladakh - A high altitude population. Am. J. Phys. Anthrop., 48: 171-178 (1978).

Malik, S.L. and Singh, I.P.: Ventilatory capacity among male Bods of Ladakh - A high altitude population. Ann. Hum. Biol., 6: 471-476 (1979).

Mandira, A.: Physical Growth and Sexual Maturation of Khatri Boys and Girls of Semi Urban Areas of Punjab Aged 6 to 19 Years. Ph.D. thesis (unpublished), Punjabi University, Patiala (1992).

Miklashevskaya, N.N. Growth and development of children in the high altitude regions of the Pamirs. Pp. 327-329. In: Human Adaptability. K. J. Collins and J. A. Weiner (Eds.). Taylor and Francis Ltd., London (1977).

Singh, S.P.: Growth patterns of children of Tibetan origin living at moderate altitudes, India. Z. Morph. Anthrop., 71: 187-195 (1980).

Singh, S.P.: Adult anthropometry, child growth and development in the Western Himalayas - A review. In 'Human Biology of Asian Highland populations in the Global Context'. (Eds.) Basu, A. and Gupta, R. 81-104 (1989).

Singh, S.P., Sidhu, L.S. and Malhotra, P.: Body morphology of high altitude Spitians of North West Himalayas. Z. Morph. Anthrop., 76: 189-195 (1986).

Weiner, J.S. and Lourie, J.A.: Human Biology - A Guide to Field Methods. Blackwell Scientific Publications, Oxford (1969). 